\title{
Renalase gene Glu37Asp polymorphism affects susceptibility to diabetic retinopathy in type 2 diabetes mellitus
}

\author{
Monika Buraczynska $^{1}$ (D) Karolina Gwiazda-Tyndel ${ }^{1} \cdot$ Bartłomiej Drop $^{2} \cdot$ Wojciech Zaluska $^{1}$
}

Received: 6 July 2020 / Accepted: 7 May 2021 / Published online: 22 June 2021

(c) The Author(s) 2021

\begin{abstract}
Aims Renalase (RNLS) is an enzyme with monoamine oxidase activity that metabolizes circulating catecholamines. The RNLS gene Asp37Glu missense polymorphism (rs2296545) has been associated with hypertension, cardiac hypertrophy and dysfunction, and stroke. The purpose of our study was to investigate the potential involvement of this polymorphism in the microvascular complications of type 2 diabetes (T2DM).

Methods In this case-control study, the polymorphism was genotyped in 860 patients with T2DM and 400 healthy controls. The genotype and allele distribution was compared in subgroups of patients: with diabetic nephropathy $(\mathrm{DN}+)(n=405)$ versus DN- (independently of the presence of $\mathrm{DR})$ and, similarly, patients with diabetic retinopathy $(\mathrm{DR}+)(n=328)$ versus DR- (independently of the presence of DN).

Results No significant association was detected between analyzed polymorphism and DN. In contrast, the retinopathy subgroup showed a significantly higher frequency of $\mathrm{G}$ allele (OR 1.4, 95\% CI 1.16-1.72, $p=0.0005)$ and GG genotype (OR 1.86, 95\% CI 1.26-2.75, $p=0.001$ ) than DR- patients. The effect of RNLS Glu37Asp polymorphism on DR remained significant after adjustments for age, gender, BMI, and duration of T2DM $(p=0.005)$.

Conclusions This is the first study to investigate RNLS gene polymorphism in microvascular complications of T2DM. The results suggest that RNLS rs2296545 SNP might be considered a risk factor for diabetic retinopathy in T2DM patients. This can provide new insight into the role of renalase gene in the pathophysiology of microvascular complications of diabetes.
\end{abstract}

Keywords Renalase gene $\cdot$ Type 2 diabetes $\cdot$ Diabetic complications $\cdot$ Polymorphism $\cdot$ Risk allele

\section{Introduction}

Type 2 diabetes mellitus (T2DM), a heterogeneous disorder of glucose metabolism, accounts for close to $90 \%$ of all diabetes cases, contributing to the burden on individuals and the health care system (American Diabetes Association 2014) [1]. Despite the availability of effective pharmacological treatments, glycemic control deteriorates and persistent hyperglycemia results in microvascular complications,

This article belongs to the topical collection Eye Complications of Diabetes, managed by Giuseppe Querques.

Monika Buraczynska

monika.buraczynska@umlub.pl

1 Department of Nephrology, Medical University of Lublin, Jaczewskiego 8, 20-950 Lublin, Poland

2 Department of Medical Informatics and Statistics, Medical University of Lublin, Lublin, Poland such as diabetic nephropathy, retinopathy, and neuropathy. Diabetic microvascular complications are the main cause of morbidity and premature mortality in patients with T2DM [2-4]. Multiple genetic and environmental factors contribute to the pathogenesis of type 2 diabetes and its complications [5]. Micro- and macrovascular complications of diabetes share some underlying pathophysiology and risk factors. Hypertension, a common comorbidity in individuals with type 2 diabetes, further contributes to macro- and microvascular complications. In this regard, renalase gene polymorphisms demonstrated a significant role in hypertension and cardiovascular complications development [6].

Renalase represents a new class of flavin-adenine dinucleotide (FAD) containing monoamine oxidases. It is expressed mainly in kidney and heart and metabolizes circulating catecholamines [7, 8]. Decreased plasma levels of renalase contribute to hypertension due to the reduced degradation of catecholamine [9]. Renalase has significant hemodynamic 
effects and is involved in the regulation of blood pressure and cardiovascular function [10-15].

Human renalase is encoded by the gene (RNLS) localized on chromosome 10 (10q23.33). It has 10 exons covering $311000 \mathrm{bp}$ [10]. Numerous single nucleotide polymorphisms (SNPs) were identified in the renalase gene, with those most studied localized at the potential functional domains. In the previous studies, several SNPs were reported to be associated with coronary heart disease $[16,17]$, stroke [18], hypertension [6, 19], and end-stage renal disease [20].

To date, most of the analyses focused on a common missense polymorphism resulting in the amino acid change (glutamic acid to aspartic acid, Glu37Asp). This polymorphism was associated with hypertension, cardiac hypertrophy and dysfunction, and ischemia [21]. Other studies also reported its association with cardiovascular disease and hypertension $[6,17,22]$.

The association between renalase gene polymorphisms and microvascular complications of diabetes has not been previously investigated. Thus, the purpose of the present study was to assess the potential involvement of renalase gene rs 2296545 polymorphism in diabetic nephropathy and retinopathy in type 2 diabetes patients.

\section{Methodology}

\section{Patients and controls}

Our study comprised 860 unrelated patients with type 2 diabetes lasting $>10$ years (mean age $59.4 \pm 9.3$ years). All enrolled subjects were Caucasian of Polish origin. Before inclusion into the study, a written informed consent was provided by all patients and healthy controls in accordance with standards of the 1964 Declaration of Helsinki. The detailed protocol of the study was approved by the institutional ethics committee.

Diabetes was diagnosed on the basis of American Diabetes Association criteria [1]. One or more of the following conditions were required for diagnosis: the classic symptoms of hyperglycemia (polyuria, polydipsia, loss of weight), fasting plasma glucose level $>7 \mathrm{mmol} / \mathrm{l}$ or random level $>11 \mathrm{mmol} / \mathrm{l}$, and the use of insulin or oral hypoglycemic medication. All subjects underwent complete physical examination that included fasting plasma glucose, glycated hemoglobin (HbA1c), full lipid profile, albumin-to-creatinine ratio (ACR), albumin excretion rate (AER), and body mass index (BMI). This was a cross-sectional study, so the patients were not matched for demographic or medical characteristics.

Upon enrollment in the study, all patients were evaluated for renal function and ophthalmological status. Their medical records were reviewed, and additional tests were performed where needed and diagnoses verified.

For analyzing the effect of renalase gene polymorphism, patients were assigned to three subgroups:

- $D N$ patients with diabetic nephropathy (with or without retinopathy);

- DR patients with diabetic retinopathy (with or without nephropathy);

- No MVC patients with no microvascular complications.

A total of 405 patients presented with diabetic nephropathy, of whom 194 patients (47.9\%) demonstrated concomitant diabetic retinopathy of any stage. Diabetic nephropathy was diagnosed in the presence of persistent albuminuria $\geq 300 \mathrm{mg} / 24 \mathrm{~h}$ in two consecutive measurements performed 1 month apart, in the absence of hematuria or infection. The presence of urinary tract infection, other renal diseases, neoplastic, rheumatological or endocrine diseases, and significant heart failure were the exclusion criteria. Patients with microalbuminuria were excluded.

Diabetic retinopathy was initially diagnosed by independent ophthalmologists in 328 patients after an eye examination including visual acuity, fundoscopic examination, and fundus photography. After enrollment in the study, findings from fundoscopic examination were assessed and verified by a retinal specialist. Retinopathy was diagnosed according to the Early Treatment Diabetic Retinopathy Study (ETDRS) criteria [23]. Exclusion criteria for the DR subgroup consisted of poor image quality, any dioptric media opacities, concomitant ocular disorders, particularly retinal vascular disorders, maculopathies, or optic nerve disorders. Patients who received recent retinal photocoagulation or intraocular surgery were also excluded.

Out of the type 2 diabetes patients, 194 had both complications, diabetic nephropathy and diabetic retinopathy.

We also included a group of 321 T2DM patients in no MVC group (mean age $58.3 \pm 9.2$ years). The clinical evaluation and complete medical documentation confirmed the lack of complications in these patients.

The control group ( $n=400$, mean age $57.5 \pm 8.1$ years) consisted of unrelated healthy volunteers (mostly blood donors and hospital staff members) who underwent health examination. They had no known history of diabetes, cardiovascular or renal disease. The subjects with the family history of these diseases in first-degree relatives were excluded. This group was first genotyped to estimate genotype/allele frequencies.

\section{Determination of rs2296545 genotype}

Genomic DNA was extracted from peripheral blood leukocytes (stored at $-70^{\circ} \mathrm{C}$ ) obtained by the standard procedure 
[24]. The RNLS SNP rs2296545 was analyzed by amplification of 209 bp DNA fragment by polymerase chain reaction (PCR). The following specific primer pair was used: forward 5'-GGAAGTCCCCGATCACGT GAC-3' and reverse 5'-TGCTGTGTGGGACAAGGCTGA-3'. Template DNA $(200 \mathrm{ng})$ was amplified in a $30 \mu \mathrm{l}$ reaction. The predenaturation step was at $95{ }^{\circ} \mathrm{C}$ for $5 \mathrm{~min}$ and was followed by 35 cycles consisting of denaturation at $95{ }^{\circ} \mathrm{C}$, annealing at $60{ }^{\circ} \mathrm{C}$, and, extension at $72{ }^{\circ} \mathrm{C}(1 \mathrm{~min}$ each $)$. The final extension step was at $72{ }^{\circ} \mathrm{C}$ for $7 \mathrm{~min}$. After PCR, the amplicon $(10 \mu \mathrm{l})$ was digested with 5 units of Eco81 I restriction endonuclease (Thermo Fisher Scientific) $\left(37^{\circ} \mathrm{C}\right.$ for $12 \mathrm{~h}$ ). The resulting DNA fragments were analyzed by electrophoresis in $2.5 \%$ agarose gel. The length of products was $188 \mathrm{bp}+21 \mathrm{bp}$ for the $\mathrm{C}$ allele and $209 \mathrm{bp}$ for the $\mathrm{G}$ allele. The quality of genotyping was controlled by using blind DNA duplicates (96 samples). The rate of concordance was $100 \%$. Also, 20 random samples for each genotype were sequenced with a forward primer by automated sequencing in the CEQ 8000 Genetic Analysis System (Beckman Coulter).

\section{Statistical analysis}

Statistical calculations were performed using SPSS 18.0 for Windows (SPSS, Inc., Chicago, IL). For comparison of baseline characteristics, the normally distributed continuous variables are presented as means \pm SD. The Hardy-Weinberg equilibrium was tested using the chi-square test. Genotype distribution and allele frequencies were compared between groups and subgroups using a chi-square test of independence with $2 \times 2$ contingency and $z$ statistics. Mann-Whitney test and Pearson's $X^{2}$ test of independence were used for comparing continuous and categorical variables. Where appropriate, the odds ratios (OR) with corresponding $95 \%$ confidence intervals (CI) were calculated for associations. An interaction of the studied polymorphism with the risk factors for diabetes and its complications was assessed with multivariate logistic regression analysis. A two-tailed type I error rate of 5\% was considered statistically significant. Post hoc power calculations were done using the available on-line power calculator.

\section{Results}

\section{Demographic and clinical characteristics}

The genotype of the rs2296545 SNP in the renalase gene was determined in 860 patients with type 2 diabetes and 400 healthy controls with genotyping success rate $100 \%$. The demographic and clinical characteristics of subjects included in the study are presented in Table 1. Among the patients with T2DM, 405 (47\%) had diabetic nephropathy, of whom 194 patients (47.9\%) had concomitant diabetic retinopathy.

Diabetic retinopathy was diagnosed in 328 patients (38\%), of whom 194 patients (59\%) had concomitant diabetic nephropathy. The gender distribution was similar in T2DM patients and control group but there was a statistically significant difference in the age at study. There was also a difference in the lipid profile and BMI between these groups. The clinical characteristics were similar between patients with diabetic nephropathy and those with diabetic retinopathy, except for triglyceride levels.
Table 1 Clinical characteristics of studied subjects

\begin{tabular}{llllll}
\hline Variables & T2DM patients & DN & DR & Without MVC & Controls \\
\hline $\mathrm{N}$ & 860 & 405 & 328 & 321 & 400 \\
Male/female ratio & $462 / 398$ & $208 / 197$ & $175 / 153$ & $161 / 160$ & $205 / 195$ \\
Age at study (years) & $59.4 \pm 9.3$ & $59.2 \pm 10$ & $58.8 \pm 9.4$ & $58.3 \pm 9.2$ & $57.5 \pm 8.1^{\mathrm{a}}$ \\
Age at diabetes diagnosis (years) & $45.2 \pm 7.3$ & $44.3 \pm 8.3$ & $43.8 \pm 8.6$ & $46 \pm 1.3^{\mathrm{b}}$ & $\mathrm{NA}$ \\
Diabetes duration (years) & $14.9 \pm 7.3$ & $14.5 \pm 8.6$ & $15.4 \pm 8.1$ & $14.0 \pm 7.2$ & $\mathrm{NA}$ \\
Cardiovascular disease (\%) & $669(77.8)$ & $318(78.6)$ & $260(79.3)$ & $209(65)^{\mathrm{b}}$ & $0^{\mathrm{a}}$ \\
Hypertension (\%) & $628(73)$ & $318(78.5$ & $246(75)$ & $218(68)$ & $0^{\mathrm{a}}$ \\
Diabetic nephropathy (\%) & $405(47.1)$ & $405(100)$ & $194(59)^{\mathrm{c}}$ & 0 & $0^{\mathrm{a}}$ \\
Diabetic retinopathy (\%) & $328(38.1)$ & $194(48)$ & $328(100)^{\mathrm{c}}$ & 0 & $0^{\mathrm{a}}$ \\
Total cholesterol (mmol/l) & $4.9 \pm 0.8$ & $4.86 \pm 1.0$ & $4.92 \pm 0.9$ & $4.6 \pm 0.76^{\mathrm{b}}$ & $4.0 \pm 0.78^{\mathrm{a}}$ \\
Triglyceride (mmol/l) $_{\text {HbA }_{1 \mathrm{c}}(\%)}^{2.3 \pm 1.26}$ & $2.3 \pm 0.96$ & $2.1 \pm 1.42^{\mathrm{c}}$ & $1.9 \pm 0.83^{\mathrm{b}}$ & $1.2 \pm 0.63^{\mathrm{a}}$ \\
${\text { BMI }\left(\mathrm{kg} / \mathrm{m}^{2}\right)}^{8}$ ) & $8.1 \pm 2.5$ & $8.3 \pm 2.7$ & $8.2 \pm 3.3$ & $8.3 \pm 2.6$ & $\mathrm{ND}^{\mathrm{a}}$ \\
\hline
\end{tabular}

$T 2 D M$ type 2 diabetes; $D N$ diabetic nephropathy (either DR+or DR-); $D R$ diabetic retinopathy (either $\mathrm{DN}+$ or DN-); $M V C$ microvascular complications; $B M I$ body mass index; $H b A_{I c}$ glycated hemoglobin; $N A$ not applicable; $N D$ not determined. For continuous characteristics values are presented as means $\pm \mathrm{SD}$. For discrete characteristics values are numbers and percentage (in parentheses). ${ }^{\mathrm{a}} p<0.05$ vs. T2DM, ${ }^{\mathrm{b}} p<0.05$ Versus. DN and DR, ${ }^{c} p<0.05$ Versus DN. Groups compared by Mann-Whitney and Pearson's $X^{2}$ tests 
Table 2 Genotype and allele distribution of Glu37Asp polymorphism in the RNLS gene in T2DM patients and controls

\begin{tabular}{|c|c|c|c|c|c|c|c|}
\hline & \multicolumn{4}{|c|}{ Genotypes } & \multirow[t]{2}{*}{ MAF } & \multicolumn{2}{|l|}{ OR $(95 \% \mathrm{CI})$} \\
\hline & $\mathrm{N}$ & $\mathrm{CC}$ & CG & GG & & $\mathrm{G}$ allele & GG genotype \\
\hline T2DM patients & 860 & $276(32)$ & $395(46)$ & $189(22)$ & 0.45 & $\begin{array}{l}0.92(0.8-1.1) \\
p=0.33\end{array}$ & $\begin{array}{l}0.88(0.6-1.2) \\
p=0.46\end{array}$ \\
\hline Controls & 400 & $108(27)$ & $208(52)$ & $84(21)$ & 0.47 & Ref & Ref \\
\hline
\end{tabular}

$T 2 D M$ type 2 diabetes mellitus; $R N L S$ renalase; $M A F$ minor allele frequency. Genotype distribution is shown as numbers (\%). Hardy-Weinberg equilibrium: $\chi^{2}=0.765, p=0.381$ for control group; $\chi^{2}=4.445$, $p=0.034$ for T2DM patients. ${ }^{\mathrm{a} C a l c u l a t e d}$ versus CC genotype

\section{Association of rs2296545 with T2DM}

Table 2 compares the distribution of the studied polymorphism in T2DM patients and healthy individuals. The frequency of genotypes for rs2296545 SNP in the control group did not deviate from the Hardy-Weinberg equilibrium $(p=0.38)$, suggesting that the subjects are representative for the population. There was a slight deviation in T2DM group $(p=0.034)$. The genotype and allele distribution did not differ significantly between the T2DM patient group and control individuals.

\section{Association of rs2296545 SNP with microvascular complications}

Genotype distribution and allele frequency were compared in the subgroups of T2DM patients with diabetic complications and those without complications. To analyze the association of the Glu37Asp polymorphism and the risk of diabetic nephropathy, we compared the genotype and allele distribution between $\mathrm{DN}+$ patients $(n=405)$ and $\mathrm{DN}-$ patients $(n=455)$. For the risk of diabetic retinopathy, $\mathrm{DR}+$ patients $(n=328)$ were compared with DR-subgroup $(n=532)$. The detailed results are presented in Table 3 . There was no statistically significant association detected between analyzed polymorphism and diabetic nephropathy. In contrast, the DR+ subgroup showed a significantly higher frequency of the G allele (OR 1.4, 95\% CI 1.16-1.72, $p=0.0005$ ) and GG genotype (OR 1.86, 95\% CI 1.26-2.75, $p=0.001)$ than DR-patients. Also, when compared with no MVC subgroup, DR+ patients had higher frequency of the risk allele (OR 1.81, 95\% CI 1.17-2.8, $p=0.0078)$. Since more than half of the DR+ patients had concomitant DN, we further analyzed the distribution of Glu37Asp polymorphism in DR + patients according to the presence or absence of DN (Table 4). The polymorphism distribution did not differ significantly between T2DM DR+ patients with and without concomitant DN.

Multiple logistic regression analysis showed that only the $R N L S$ gene polymorphism was a significant predictor of diabetic retinopathy. The effect of RNLS Glu37Asp polymorphism on diabetic retinopathy remained significant even after adjustments for age, gender, BMI, and duration of T2DM $(p=0.005)$ (Table 5). Table 6 shows comparison of clinical characteristics between patients with and without diabetic retinopathy. Patients in DR-subgroup were older than those in DR+ subgroup. The proportion of patients who also had nephropathy was significantly lower in DR - than in the DR+ subgroup. Plasma lipids and other metabolic parameters showed no difference between the
Table 3 Genotype and allele distribution of Glu37Asp polymorphism in the RNLS gene in subgroups of T2DM patients

\begin{tabular}{|c|c|c|c|c|c|c|c|}
\hline & \multicolumn{4}{|c|}{ Genotypes } & \multirow[t]{2}{*}{ MAF } & \multicolumn{2}{|l|}{ OR $(95 \%$ CI $)$} \\
\hline & $\mathrm{N}$ & $\mathrm{CC}$ & CG & GG & & $\mathrm{G}$ allele & GG genotype ${ }^{a}$ \\
\hline T2DM DN+ & 405 & $114(28)$ & $198(49)$ & $93(23)$ & 0.47 & $\begin{array}{l}1.2(0.99-1.46) \\
p=0.052\end{array}$ & $\begin{array}{l}1.37(0.94-1.99) \\
p=0.092\end{array}$ \\
\hline T2DM DN- & 455 & $162(36)$ & $197(43)$ & $96(21)$ & 0.43 & Ref & Ref \\
\hline T2DM DR+ & 328 & $78(24)$ & $170(52)$ & $80(24)$ & 0.50 & $\begin{array}{l}1.41(1.16-1.72) \\
p=0.0005\end{array}$ & $\begin{array}{l}1.86(1.26-2.75) \\
p=0.001\end{array}$ \\
\hline T2DM DR- & 532 & $198(38)$ & $225(42)$ & $109(20)$ & 0.42 & Ref & Ref \\
\hline T2DM without MVC & 321 & $113(35)$ & $144(45)$ & $64(20)$ & 0.42 & $\begin{array}{l}1.37(1.1-1.71)^{\mathrm{b}} \\
p=0.0042\end{array}$ & $\begin{array}{l}1.81(1.17-2.8)^{\mathrm{b}} \\
p=0.0078\end{array}$ \\
\hline
\end{tabular}

$T 2 D M$ type 2 diabetes mellitus; $R N L S$ renalase; $M A F$ minor allele frequency; $D N$ diabetic nephropathy (either DR+or DR-); $D R$ diabetic retinopathy (either $\mathrm{DN}+$ or DN-); $M V C$ microvascular complications. Genotype distribution is shown as numbers (\%). ${ }^{\mathrm{a} C a l c u l a t e d}$ versus $\mathrm{CC}$ genotype. ${ }^{\mathrm{b}} \mathrm{Calculated}$ versus T2DM with DR subgroup 
Table 4 Genotype and allele distribution of Glu37Asp polymorphism in the RNLS gene in the T2DM DR+ patients according to the presence or absence of DN

\begin{tabular}{|c|c|c|c|c|c|c|c|}
\hline & \multicolumn{4}{|c|}{ Genotypes } & \multirow[t]{2}{*}{ MAF } & \multicolumn{2}{|l|}{ OR $(95 \% \mathrm{CI})$} \\
\hline & $\mathrm{N}$ & $\mathrm{CC}$ & $\mathrm{CG}$ & GG & & $\mathrm{G}$ allele & GG genotype ${ }^{a}$ \\
\hline $\mathrm{T} 2 \mathrm{DM} \mathrm{DR}+\mathrm{DN}-$ & 134 & $35(26)$ & $66(49)$ & $33(25)$ & 0.49 & $\begin{array}{l}1.38(1.03-1.84) \\
p=0.028\end{array}$ & $\begin{array}{l}1.66(0.94-2.93) \\
p=0.047\end{array}$ \\
\hline T2DM DR+DN+ & 194 & $43(22)$ & $104(54)$ & $47(24)$ & 0.51 & $\begin{array}{l}1.42(1.1-1.82) \\
p=0.006\end{array}$ & $\begin{array}{l}1.76(1.06-2.93) \\
p=0.028\end{array}$ \\
\hline T2DM without MVC & 321 & $113(35)$ & $144(45)$ & $64(20)$ & 0.42 & ref & ref \\
\hline
\end{tabular}

$T 2 D M$ type 2 diabetes mellitus; $R N L S$ renalase; $M A F$ minor allele frequency; $D N$ diabetic nephropathy; $D R$ diabetic retinopathy; $M V C$ microvascular complications. Genotype distribution is shown as numbers (\%). ${ }^{\mathrm{a} C}$ Calculated versus CC genotype. OR calculated for DR+DN-versus DR+DN+was 0.93 (0.68-1.27), $p=0.654$ and $0.88(0.43-1.62), p=0.645$, for the $\mathrm{G}$ allele and $\mathrm{GG}$ genotype, respectively
Table 5 Multivariate logistic regression analysis

\begin{tabular}{llll}
\hline Variable & Odds ratio & $95 \%$ CI & $p$ value \\
\hline Age at study & 1.16 & $0.73-1.41$ & 0.07 \\
Gender & 1.28 & $0.82-1.67$ & 0.09 \\
T2DM duration & 1.19 & $0.72-1.83$ & 0.13 \\
BMI & 1.12 & $0.92-1.21$ & 0.24 \\
G allele* & 1.37 & $1.19-2.06$ & 0.005 \\
\hline
\end{tabular}

T2DM type 2 diabetes mellitus. *RNLS Glu37Asp polymorphism An unconditional model of multiple logistic regression analysis was used for interaction of $R N L S$ gene polymorphism with other variables

Table 6 Clinical characteristics of T2DM patients with and without retinopathy

\begin{tabular}{llll}
\hline Variables & DR+ & DR- & $P$ value \\
\hline $\mathrm{N}$ & 328 & 532 & \\
Male/female ratio & $175 / 153$ & $287 / 245$ & 0.886 \\
Age at study (years) & $58.8 \pm 9.4$ & $60 \pm 9.2$ & 0.065 \\
Age at diabetes diagnosis (years) & $43.8 \pm 8.6$ & $46.7 \pm 5.9$ & 0.0001 \\
Diabetes duration (years) & $15.4 \pm 8.1$ & $14.4 \pm 6.5$ & 0.046 \\
Cardiovascular disease (\%) & $260(79.3)$ & $409(76.8)$ & 0.302 \\
Diabetic nephropathy (\%) & $194(59)$ & $211(39.6)$ & $<0.0001$ \\
Total cholesterol (mmol/l) & $4.92 \pm 0.9$ & $4.88 \pm 0.8$ & 0.497 \\
Triglyceride (mmol/l) & $2.1 \pm 1.42$ & $2.5 \pm 1.2$ & $<0.0001$ \\
HbA $_{1 \mathrm{c}}(\%)$ & $8.2 \pm 3.3$ & $8.0 \pm 1.6$ & 0.234 \\
${\text { BMI }\left(\mathrm{kg} / \mathrm{m}^{2}\right)}$ & $28.2 \pm 9.3$ & $28.6 \pm 7.9$ & 0.5 \\
\hline
\end{tabular}

$T 2 D M$ type 2 diabetes; $D R$ diabetic retinopathy (either $\mathrm{DN}+$ or $\mathrm{DN}-$ ). For continuous characteristics values are presented as means $\pm \mathrm{SD}$. For discrete characteristics values are numbers and percentage (in parentheses)

subgroups except for triglyceride levels that were higher in DR-patients.
Among 328 patients with diabetic retinopathy, 134 (41\%) had proliferative retinopathy (PDR). When compared between NPDR and PDR patients, there were no significant differences in the Glu37Asp allele and genotype distribution between these subgroups $(p>0.05)$.

\section{Discussion}

The macrovascular and microvascular complications of diabetes share some pathophysiology and conventional as well as genetic risk factors. The previous studies demonstrated that renalase gene polymorphisms are involved in the macrovascular complications of diabetes, such as hypertension and cardiovascular disease $[6,16,17,21$, $25,26]$. Therefore, in the present case-control study, we aimed to assess the potential involvement of the RNLS gene rs2296545 polymorphism in microvascular complications of type 2 diabetes mellitus.

It was previously documented that renalase is involved in diabetes and its clinical features. The levels of renalase in the T1DM and T2DM groups of patients were significantly higher than in control group and were correlated with changes in blood pressure, glomerular filtration, and insulin resistance [15]. In our study no statistically significant differences were observed when the distribution of polymorphism was compared between T2DM patients and healthy controls. This replicates the result from our previous study, where rs2296545 polymorphism was associated with hypertension in type 2 diabetes patients but not with diabetes itself [18]. At present, there are no other molecular studies published on the effects of the renalase gene polymorphisms in type 2 diabetes. There are some reports from linkage and association studies, linking the renalase gene with type 1 diabetes, and suggesting an immune basis for the disease. In a genome-wide association study, the human leukocyte antigen (HLA) region, affecting the risk of T1DM, contained the rs10509540 SNP in the renalase gene [27]. Another study of T1DM-associated regions 
confirmed a potential role of renalase in the development of autoimmune pancreatic $\beta$-cell destruction [28]. The rs 10509540 polymorphism has been shown to have, in interaction with IL-2 gene polymorphism, an age-at-diagnosis effect on pediatric-onset T1DM [29]. The association was also found between RNLS rs 10887800 polymorphism and gestational diabetes mellitus [30].

We further assessed the polymorphism distribution in the subgroups of T2DM patients with diabetic nephropathy and retinopathy. While there was no association detected between this SNP and diabetic nephropathy, the retinopathy subgroup showed a significant association of the $G$ allele with DR. This association remained significant after adjustment for age, gender, BMI, and duration of T2DM. The polymorphism distribution did not differ significantly between T2DM DR+ patients with and without concomitant DN. These findings demonstrate that the renalase gene polymorphism is associated with susceptibility to retinopathy in type 2 diabetes. The reason for the discrepancy in the effect of rs2296545 polymorphism between DR and DN is unclear at this point. It might be related to heterogeneity in the genetic susceptibility due to different pathophysiological pathways in the development of these microvascular complications. It is also possible that the effect size on the renal outcome might be much smaller than on ocular outcome. The lack of association of the studied polymorphism with diabetic nephropathy is difficult to explain in the light of the links between renalase and kidney disease widely described in the literature. Concentrations of renalase in serum are significantly higher in patients with chronic kidney disease (CKD) than in control group and are elevated in the increasing stage of renal failure [31-33]. Zbroch et al. described a significant inverse correlation between the serum renalase and residual renal function [34]. In an elegant study on the role of renalase in diabetic renal injury, using a mouse model of renalase knockout mice, the authors showed the protective role of renalase in DN. The heterozygous knockout of renalase in $\mathrm{db} / \mathrm{db}$ mouse caused an exacerbation of albuminuria, mesangial expansion, and renal injury progression. These symptoms were ameliorated with renalase overexpression in $\mathrm{db} / \mathrm{db}$ mice. Renalase exerted the protective effects in DN through inhibition of mesangial cell hypertrophy, oxidative stress, and inflammation [35]. The results of the molecular studies also showed a linkage between the renalase gene polymorphisms and kidney diseases [36, 37].

The exact mechanism of association between Glu37Asp polymorphism in the renalase gene and the risk of developing DR is not clear yet and requires further, larger studies, also on the cellular level. The mechanisms that initiate and control the progress of diabetic retinopathy are still unclear. It is hard to explain why not all patients after a long diabetes duration, even with poor glycemia, develop DR. On the other hand, some patients with good glycemic control develop a vision-threatening DR. Our finding could be interpreted as an effect of the rs 2296545 polymorphism on certain clinical or metabolic factors associated with retinopathy. Endothelial dysfunction plays a crucial role in the early pathophysiology of vascular complications of diabetes [38]. Yun et al. identified endothelial dysfunction as an independent predictor of an increased DR prevalence in patients with T2DM [39]. The progressive dysfunction of endothelial cells contributes to the retinal morphological and pathophysiological changes: thickening of capillary basement membrane, perivascular cell loss, damage of blood-retina barrier, and neovascularization [40, 41]. An important feature of endothelial dysfunction is an increased production and biological activity of the potent vasoconstrictor and proinflammatory peptide endothelin-1 (ET-1). Several lines of evidence suggest that the ET-1 system contributes to diabetic vascular disorders. Elevated renalase levels increase serum ET-1 levels, thus aggravating endothelial dysfunction and vasoconstriction [33]. Vascular and extravascular sites in the retina are a rich source of ET-1 expression. The ET-1 impairs the autoregulation of retinal blood flow, which can cause hyperperfusion, promoting formation of retinal microaneurysms and edema [42]. On the other hand, ET-1-mediated vasoconstriction can trigger a hypoxic state which later leads to pathological angiogenesis as seen in diabetic retinopathy [43]. The relationship between ET-1 plasma concentration and a degree of progression of DR has been demonstrated in many studies [44]. Although the role of renalase in endothelial function might be an important factor in developing DR, this mechanism is still unclear and requires further biological and functional studies.

The results obtained in our study should be interpreted with caution. The rs 2296545 SNP is located in exon 2 of the RNLS gene and, therefore, it might change the gene functions via affecting the protein structure or function. However, to date, there have been no results from functional studies published to support this speculation. The important limitation of our study is that we did not also analyze the functional consequences of this polymorphism. The determinations of serum renalase levels or its enzymatic activity were not performed in the study subjects.

In conclusion, to the best of our knowledge, this is the first published study investigating the effect of the RNLS gene polymorphism on microvascular complications of diabetes. Our findings demonstrate that the rs 2296545 polymorphism in the renalase gene is associated with increased susceptibility to retinopathy in type 2 diabetes patients. A novel observation of this association as well as its clinical significance needs to be confirmed in further, larger studies.

Funding This research did not receive any specific grant from funding agencies in the public, commercial, or non-for-profit sectors. 


\section{Declarations}

Conflict of interest All authors declare that they have no conflict of interest.

Ethical approval The study was approved by the local Ethical Committee (KE-0254/282/2018).

Human and animal rights All procedures performed in this study involving human participants were in accordance with the ethical standards of the institutional research committee and with the 1964 Helsinki Declaration and its later amendments or comparable ethical standards.

Informed consent Written informed consent was obtained from all participants included in the study.

Open Access This article is licensed under a Creative Commons Attribution 4.0 International License, which permits use, sharing, adaptation, distribution and reproduction in any medium or format, as long as you give appropriate credit to the original author(s) and the source, provide a link to the Creative Commons licence, and indicate if changes were made. The images or other third party material in this article are included in the article's Creative Commons licence, unless indicated otherwise in a credit line to the material. If material is not included in the article's Creative Commons licence and your intended use is not permitted by statutory regulation or exceeds the permitted use, you will need to obtain permission directly from the copyright holder. To view a copy of this licence, visit http://creativecommons.org/licenses/by/4.0/.

\section{References}

1. American diabetes association (2014) Standards of medical care in diabetes-2014. Diabetes Care 37 (suppl. 1): 14-80

2. He Z, King GL (2004) Microvascular complications of diabetes. Endocr Metab Clin North Am 33:215-238

3. Faselis C, Katsimardou A, Imprialos K, Deligkaris P, Kallistratos M, Dimitriadis K (2019) Microvascular complications of type 2 diabetes mellitus. Curr Vasc Pharmacol. https://doi.org/10.2174/ 1570161117666190502103733

4. Visaria J, Iver NN, Raval A, Kong S, Hobbs T, Bouchard J et al (2019) Incidence and prevalence of microvascular and macrovascular diseases and all-cause mortality in type 2 diabetes mellitus: a 10 -year study in a US commercially insured and medicare advantage population. Clin Ther 41:1522-1536

5. O'Rahilly S, Barroso I, Wareham NJ (2005) Genetic factors in type 2 diabetes: the end of the beginning? Science 307:370-373

6. Zhao Q, Fan Z, He J, Chen S, Li H, Zhang P et al (2007) Renalase gene is a novel susceptibility gene for essential hypertension: a two-stage association study in Northern Han Chinese population. J Mol Med 85:877-885

7. Luft FC (2005) Renalase, a catecholamine-metabolizing hormone from kidney. Cell Metab 1:358-360

8. Xu J, Li G, Wang P, Velazques H, Yao X, Li Y et al (2005) Renalase is a novel, soluble monoamine oxidase that regulates cardiac function and blood pressure. J Clin Invest 115:1275-1280

9. Desir G (2012) Novel insights into the physiology of renalase and its role in hypertension and heart disease. Pediatr Nephrol 27:719-725

10. Desir GV (2008) Renalase deficiency in chronic kidney disease, and its contribution to hypertension and cardiovascular disease. Curr Opin Nephrol Hypertens 7:181-185
11. Desir GV (2009) Regulation of blood pressure and cardiovascular function by renalase. Kidney Int 76:366-370

12. Li X, Huang R, Xie Z, Lin M, Liang Z, Yang Y, Jiang W (2014) Renalase, a new secretory enzyme: its role in hypertensiveischemic cardiovascular diseases. Med Sci Monit 20:688-692

13. Milani M, Ciriello F, Baroni S, Pandini V, Canevari G, Bolognesi $\mathrm{M}$ et al (2011) FAD-binding site and NADP reactivity in human renalase: a new enzyme involved in blood pressure regulation. $\mathrm{J}$ Mol Biol 411:463-473

14. Fedchenko V, Globa A, Buneeva O, Medvedev A (2013) Renalase mRNA levels in the brain, heart, and kidneys of spontaneously hypertensive rats with moderate and high hypertension. Med Sci Monit Basic Res 19:267-270

15. Wang F, Huang B, Li J, Liu L, Wu N (2014) Renalase might be associated with hypertension and insulin resistance in type 2 diabetes. Ren Fail 36:552-556

16. Hu N, Wang J, Hu P, Li Z (2018) Investigation of renalase gene rs2576178 polymorphism in patients with coronary artery disease. Biosci Rep 38:1-5

17. Li X, Jiang W, Li L, Huang R, Yang Q, Yang Y et al (2014) Renalase gene polymorphism in patients with hypertension and concomitant coronary heart disease. Kidney Blood Press Res 39:9-16

18. Buraczynska M, Zukowski P, Buraczynska K, Mozul S, Ksiazek A (2011) Renalase gene polymorphisms in patients with type 2 diabetes, hypertension and stroke. Neuromol Med 13:321-327

19. Bagci B, Karakus S, Bagci G, Sancakdar E (2016) Renalase gene polymorphism is associated with increased blood pressure in preeclampsia. Pregnancy Hypertens 6:115-120

20. Stec A, Semczuk A, Furmaga J, Ksiazek A, Buraczynska M (2012) Polymorphism of the renalase gene in end-stage renal disease patients affected by hypertension. Nephrol Dial Transplant 27:4162-4166

21. Farzaneh-Far R, Desir GV, Na B, Schiller NB, Whooley MA (2010) A functional polymorphism in renalase (Glu37Asp) is associated with cardiac hypertrophy, dysfunction and ischemia: data from the heart and soul study. PLOS One 5:e13496

22. Orlowska-Baranowska E, Gadomska Vel Betka L, Gora J, Baranowski R, Pedzich-Placha E, Zakrzewski D et al (2017) Functional polymorphism of the renalase gene is associated with cardiac hypertrophy in female patients with aortic stenosis. PLOS One. https://doi.org/10.1371/journal.pone.0186729

23. Early treatment diabetic retinopathy study research group (1991) Grading diabetic retinopathy from stereoscopic color fundus photographs-an extension of the modified airlie house classification. ETDRS report number 10. Ophthalmology 98 (5) (supp 1): 786-806

24. Madisen L, Hoar DI, Holroyd CD, Crisp M, Hodes ME (1987) DNA banking: the effects of storage of blood and isolated DNA on the integrity of DNA. Am J Med Genet 27:379-390

25. Zhang R, Li X, Liu N, Guo X, Liu W, Ning C et al (2013) An association study on renalase polymorphisms and ischemic stroke in a Chinese population. Neuro Mol Med 15:396-404

26. Stec A, Ksiazek A, Buraczynska M (2016) Rs 10887800 renalase gene polymorphism is associated with an increased risk of coronary artery disease in hemodialyzed patients. Int Urol Nephrol 48:871-876

27. Barrett JC, Clayton DG, Concannon P et al (2009) Genomewide association study and meta-analysis find that over 40 loci affect risk of type 1 diabetes. Nat Genet 41:703-707

28. Wallace C, Rotival M, Cooper JD et al (2012) Statistical colocalization of monocyte gene expression and genetic risk variants for type 1 diabetes. Hum Mol Genet 21:2815-2824

29. Howson J, Cooper JD, Smyth DJ, Walker NM, Stevens H, She JX et al (2012) Evidence of gene-gene interaction and age-atdiagnosis effects in type 1 diabetes. Diabetes 61:3012-3017 
30. Fatima SS, Jamil Z, Alam F, Malik HZ, Madhani SI, Ahmad MS et al (2017) Polymorphism of the renalase gene in gestational diabetes mellitus. Endocrine 55:124-129

31. Stojanovic D, Cvetkovic T, Stojanovic M, Bojanic V, Stefanovic N, Stojanovic I (2015) The assessment of renalase: searching for the best predictor of early renal dysfunction by multivariate modeling in stable renal transplant recipients. Ann Transplant 20:186-192

32. Zbroch E, Musialowska D, Koc-Zorawska E, Malyszko J (2016) Age influence on renalase and catecholamines concentration in hypertensive patients, including maintained dialysis. Clin Interv Aging 11:1545-1550

33. Li YH, Sheu WH, Lee WJ, Wang JS, Fu CP, Liang KW et al (2018) Synergistic effect of renalase and chronic kidney disease on endothelin-1 in patients with coronary artery disease-a cross sectional study. Sci Rep 8:7378. https://doi.org/10.1038/ s41598-018-25763-4

34. Zbroch E, Malyszko J, Malyszko JS, Koc-Zorawska E, Mysliwiec M (2012) Renalase, a novel enzyme involved in blood pressure regulation, is related to kidney function but not too blood pressure in hemodialysis patients. Kidney Blood Press Res 35:385-389

35. Yin J, Liu X, Zhao T, Liang R, Wu R, Zhang F et al (2020) A protective role of renalase in diabetic nephropathy. Clin Sci (Lond) 134:75-85

36. Ahlawat RS, Gupta S, Kapoor AS, Kar P (2012) Polymorphism of renalase gene in patients of chronic kidney disease. O J Neph 2:136-143

37. Rezk NA, Zidan HE, Elnaggar YA, Ghorab A (2015) Renalase gene polymorphism and epinephrine level in chronic kidney disease. Appl Biochem Biotechnol 175:2309-2317
38. Creager MA, Luscher TF, Cosentino F et al (2003) Diabetes and cardiovascular disease pathophysiology, clinical consequences, and medical therapy; part 1. Circulation 108:1527-1532

39. Yun JS, Ko SH, Kim JH, Moon KW, Park YM, Yoo KD et al (2013) Diabetic retinopathy and endothelial dysfunction in patients with type 2 diabetes mellitus. Diabetes Metab J 37:262-269

40. Sorrentino FS, Matteini S, Bonifazzi C, Sebastiani A, Parmeggiani F (2018) Diabetic retinopathy and endothelin system: microangiopathy versus endothelial dysfunction. Eye 32:1157-1163

41. Al-Kharashi AS (2018) Role of oxidative stress, inflammation, hypoxia and angiogenesis in the development of diabetic retinopathy. Saudi J Ophthalmology 32:318-323

42. Kohner EM, Patel V, Rassam SMB (1995) Role of blood flow and impaired autoregulation in the pathogenesis of diabetic retinopathy. Diabetes 44:603-607

43. Ergul A (2011) Endothelin-1 and diabetic complications: focus on the vasculature. Pharmacol Res 63:477-482

44. Laurenti O, Vingolo EM, Desidori GB, Ferri C, Bellini C, Cassone-Faldetta $\mathrm{M}$ et al (1997) Increased levels of plasma endothelin-1 in non-insulin dependent diabetic patients with rewtinopathy but without other diabetes-related organ damage. Exp Clin Endocrinol Diabetes 105:40-42

Publisher's Note Springer Nature remains neutral with regard to jurisdictional claims in published maps and institutional affiliations. 